\title{
Correction: Prevalence and predictors for sustained remission in rheumatoid arthritis
}

Yoon-Kyoung Sung, Kazuki Yoshida, Femke H. M. Prince, Michelle L. Frits, SooKyung Cho, Jung-Yoon Choe, Hye-Soon Lee, Jisoo Lee, Shin-Seok Lee, Dae-Hyun Yoo, Simon M. Helfgott, Nancy A. Shadick, Michael E. Weinblatt, Daniel H. Solomon, SangCheol Bae

The email address listed for the corresponding author, Yoon-Kyoung Sung, is incorrect. The correct email address for the corresponding author is: sungyk@hanyang.ac.kr.

\section{Reference}

1. Sung Y-K, Yoshida K, Prince FHM, Frits ML, Cho S-K, Choe J-Y, et al. (2019) Prevalence and predictors for sustained remission in rheumatoid arthritis. PLoS ONE 14(4): e0214981. https://doi.org/10. 1371/journal.pone.0214981 PMID: 31002669

\section{f open access}

Citation: Sung Y-K, Yoshida K, Prince FHM, Frits ML, Cho S-K, Choe J-Y, et al. (2019) Correction: Prevalence and predictors for sustained remission in rheumatoid arthritis. PLOS ONE 14(8): e0221314. https://doi.org/10.1371/journal. pone. 0221314

Published: August 14, 2019

Copyright: ๑ 2019 Sung et al. This is an open access article distributed under the terms of the Creative Commons Attribution License, which permits unrestricted use, distribution, and reproduction in any medium, provided the original author and source are credited. 